\title{
Communication support as a factor in the effectiveness of the innovative subsystem and the formation of poles of sustainable development of the region
}

\author{
Alexander Evmenov ${ }^{1}$, Eduard Krolivetsky ${ }^{1,}{ }^{,}$, Svetlana Krolivetskaya ${ }^{2}$, and Taisiya Sorvina ${ }^{1}$ \\ ${ }^{1}$ St. Petersburg State Institute of Cinema and Television, 13, ul. Pravdi st., St. Petersburg, Russia \\ ${ }^{2}$ Russian Academy of National Economy and Public Administration, 4, nab. Pesjchnaya, St. \\ Petersburg, Russia
}

\begin{abstract}
The article actualizes the importance of communication support for the process of efficient use of regional innovative subsystems in the conditions of insufficient development of this problem in the economic literature. The necessity of creating a communication support mechanism within a regional innovation subsystem is substantiated, its essence, the principles of construction, as an element of the regional innovation subsystem functioning control are revealed. The scheme of interaction of information and analytical functions of the regional mechanism of communication support of the innovation system of the region is described. The service nature of the participation of elements of the communication support mechanism in the management of innovative processes in the region, as a component of the regional development pole, is determined.
\end{abstract}

\section{Introduction}

The importance of communications, as a combination of methods, means and tools of data transmission, in modern conditions of functioning of socio-economic systems is determined by the fact that development processes on a global transnational scale represent the formation of an information society, "in which information and the level of its application and accessibility radically affect on the economic and sociocultural living conditions of citizens"[1]. The creation of an information society, as a new social structure, involves significant changes in the basic resource parameters of public life. Thus, a significant and ever-growing part of the labor potential is concentrated in areas that provide for the generation, accumulation, transformation and transmission of information, which involves a number of radical technological changes (methods for creating and distributing information). These changes, in turn, determine new requirements for the vocational qualification structure of the workforce and for the investment structure, the most effective strategic directions of which are the areas of the economy that form and distribute information flows [2]. The need for state participation in creating the conditions for the

${ }^{*}$ Corresponding author: getman-greta@mail.ru 
functioning of the national economy, adequate to the specifics of the new social structure, led to the adoption of the Program for the Development of the Information Society in the Russian Federation [3] (hereinafter - the Program). The general goals of the Program are the growth of the quality of the socio-economic environment, the creation of effective conditions for the functioning of business entities and the general economic growth of the state based on the widespread introduction of modern information and telecommunication technologies. It should be noted that, as key links, the Program includes the subprograms "Information and telecommunication infrastructure of the information society and services provided on its basis", "Information environment" and "Security in the information society", the implementation of which involves the creation of the material and technical and personnel basis of modern communications whose subjects are the widest sections of the population and organizations of various profiles of activity.

The regional aspect of creating the information society is reflected in the Program in accordance with the provisions of the Concept of Regional Informatization [4], where the priority is "ensuring the unity, stability and security of the information and telecommunication infrastructure of the Russian Federation at all levels of the information space" (paragraph II of the Program "General characteristics of the participation of the constituent entities of the Russian Federation in the implementation of the Program "). The solution to this problem must be ensured in compliance with the principle formulated as "the use of information technology to solve the priority tasks of the socio-economic development of the constituent entities of the Russian Federation, improving the management system of the constituent entities of the Russian Federation" (ibid.). In the context of the focus of this work, the implementation of this principle involves the orientation of the information technology and communication support of the socioeconomic sphere of the regions to participate in the innovative development of the federation by creating effective development poles in them.

The element of the information society of the subject of the federation that determines the development potential of the territory is the region's innovation system (regional innovation subsystem (The use of the terms "system" and "subsystem" is determined by the level of the object being studied: an object representing a higher level of hierarchy (the limit for this study) is recognized by the system, lower - by the subsystem (provided that each of them has signs of structural complexity, connectivity and target orientation ) Moreover, the general properties of the system and subsystem are identical and the methods and tools of system research are fully applicable to any of these objects [5])), which in the general sense can be characterized as an integral combination of subjects (control elements) and objects (controlled elements) involved in the creation and application of scientific technical innovations in order to obtain a given result (economic, social, environmental, integrated) and implementing these processes as The main type of activity (global function).

\section{Applied methodology, research materials}

A qualitative study was carried out, the main presupposition for which the authors consider the opportunity to analyze and identify the efficient use of regional innovative subsystems. The forecasting of the medium-term estimates are obtained by economic and mathematical methods with a representative sample (dynamic economic indicators), as well as expert methods. The paper considers the research methodology in the whole. 


\subsection{Review}

Studies in the methodology and practice of the formation of innovative regional systems have revealed a number of problems, the solution of which seems necessary to increase the effectiveness of the functioning of development poles in general and especially if they are created in the conditions of the constituent entities of the Russian Federation.

In [6], the concept of "the region's ability to learn" is introduced, which is interpreted as the level of perception of innovations by elements of the regional innovation system, which is shaped by a large number of internal factors (geographical, demographic, sociocultural, economic, political, and others) and determines the importance of competitive advantages of the territory. The ability of a region to learn, in our opinion, is largely determined by the quality of its communication environment, which can to a greater or lesser extent facilitate the acquisition by economic entities of the information necessary for their development (in the terminology of K. Morgan - transfer of knowledge), determining its volume, relevance and adequacy to the needs of the development of the innovation system of the subject of the federation.

The study [7], devoted to the peculiarities of the development of regional innovation systems in a globalized economy, reveals a rational level of autonomy (closeness) of such systems and shows that their competitiveness is due to the active interaction with organizations and enterprises in the region, as well as with external entities in first of all, with innovative systems of other regions, with national and transnational innovative systems. According to our ideas, a full-fledged interaction of this kind is possible only under the conditions of a developed communication mechanism, which includes a set of modern technical and software tools for information exchange.

In [8], as one of the important problems of creating a system for managing the development of the regions of the Russian Federation, the insufficiency of existing information links between the real sector of the economy of the subject of the federation, its financial component, academic organizations and public authorities is proved, which is a factor negatively affecting innovation activity and requires urgent measures to create a mechanism for direct and reverse horizontal and vertical communications (closed the circuit).

The fundamental importance of institutions as a determining factor in the effectiveness of a regional innovation system was proved in [9, 10], where institutions and the institutional environment are called its basic elements (Under the institute in modern economic theory is understood the totality of subject-specific specialized norms and rules governing a certain aspect of the functioning of the subject of the economy, while the institutional environment is a set of institutions that determine the possibilities of the subject as a whole [11].).

\subsection{The treatment of institutional principles}

Institutional economics as one of the basic provisions puts forward the thesis that the composition of institutions, as an integral mechanism for regulating economic activity, should adequately reflect all its essential aspects, which ensures compliance with a number of fundamental requirements, most accurately expressed in the principles of institutocentrism, holism (methodological collectivism), distinction, behaviorism and historicism (The composition and interpretation of the principles of institutionalism in various fundamental (for example, $[12,13,14]$ and others) and modern (for example, $[15$, $16,17]$ and others) works on institutional economics differ significantly; in our text, a compilation of the most representative opinions of recognized scientists is proposed.). Each of these principles, when applied to the processes of formation and management of the 
development of an effective regional innovation system, is concretized in accordance with the specifics of the object and should be interpreted as:

- the principle of institution-centrism, which assumes that when forming the norms and rules of innovative activity in the region, it is necessary to proceed from its secondary nature with respect to the global (central) task of improving the quality of life of the population of the subject of the federation and consider it as an existential element of society functioning in a certain geographical, political and cultural environment;

- the principle of holism (methodological collectivism), according to which the institutions of innovative activity should comprehensively reflect the ties in the regional innovation system, in which the highest hierarchical position is taken by the entity performing the function of harmonizing the interests of individual individuals - participants in the process of creating and applying scientific and technological innovations by developing common them regulations;

- the principle of distinction (irreducibility) reflects the radical differences between the social and operational aspects of innovation and makes it necessary to consider the innovation system of the subject of the federation primarily as a socio-economic mechanism and, therefore, orient the institutional regulation of its functioning towards the creation of social conditions for scientific and technical activity;

- the principle of behaviorism consists in the requirement of constructing a regional innovation system that, through institutional mechanisms, determines the forms and methods of behavior of subjects of innovative activity and ensures harmonization of compliance with their local interests and the need to solve specific problems of socioeconomic development of the subject of the federation;

- the principle of historicism, in accordance with which the process of institutional support of the functioning of the regional innovation system should be considered in the context of the dynamics of the transformation of federal institutions and institutes of the subject of the federation and develop solutions in the field of regulatory (imperative) and regulatory coordination (consensus) regulation of innovation with existing basis and based on objective trends of its change.

A solution to the problem of institutional support for the creation and development of a regional innovation system based on strict observance of the above principles in a federal state is possible only if there is a wide exchange of information in the form of vertical (federal center - regions) and horizontal (interregional) flows formed through modern means of communication. The use of a communication mechanism that is functionally and organizationally adequate to the needs of national and regional innovation systems will allow to dampen objectively existing contradictions in the interests of public and private actors in the management of innovative processes and to develop agreed norms and rules for conducting innovative activities.

An analysis of approaches to studying and solving the problems of increasing the efficiency of regional innovation systems allows us to characterize the regional innovation subsystem as an element of the socio-economic sphere of a federation subject in accordance with the goals and objectives of our study, the purpose of which is to create operational and institutional institutions corresponding to the specifics of this territory (federation subject) conditions for using the achievements of science and technology to create new high consumer products values. The degree of achievement of this goal should be recognized as a generalizing criterion characteristic of the effectiveness of the functioning of the innovation system of the subject of the federation, the level of which is determined by how much the results of socio-economic development correspond to the growth parameters established in the regional strategic program documents. 


\subsection{The development pole in the regional innovation subsystem}

The possibility of objectively substantiated high values of such parameters requires, according to the position of the authors on the problem of sustainable growth of the subject of the federation, the selection in the regional innovation subsystem of that part (an integral set of elements) that should fulfill the functions of the development pole and for which it is necessary to provide special tools for an integrated resource ( material, technical, personnel and financial) support $[18,19,20]$.

The effective functioning of both the pole of regional development, which is the basic element of the regional innovation subsystem, and the subsystem as a whole suggests its active external interaction with partners in innovation. Such partners may include elements of socio-economic systems and development poles of other regions, all subsystems of a given region (for example, other components of this innovative subsystem, educational, production, logistics and distribution subsystems of a federation subject and others). The internal interaction of its elements has a fundamental importance and allow to ensure the integrity of the innovation process, is important for achieving the goal of the regional pole of innovative development. An important condition for achieving this goal should be recognized as the precise regulation of interaction processes by creating a rational institutional environment for innovation. From these positions, one of the key tasks for the effective functioning of the regional innovation subsystem is the formation of a functionally and institutionally sound mechanism for communication support of organizations and enterprises included in the development pole of the subject of the federation.

The basis for the creation of a communication support mechanism capable of acting as one of the determining factors for rationalizing the region's innovation system based on the formation of regional development poles should be based on concepts and approaches developed within the framework of the general theory of communications.

It seems fully justified to classify the innovation system of the subject of the federation as a technological class, which, according to GOST 27.004-85 [21], acts as "a set of functionally interconnected means of technological equipment, production items and performers for performing specified technological processes or operations in regulated production conditions". This provision is based on the fact that the overall operational function of such a system is the implementation of a set of innovative processes that require adequate technological equipment (from laboratory equipment to production fixed assets), the use of a variety of production items (from research materials to components for production) and the use of wide the circle of performers of various professions (from scientists to production workers). This aspect of the representation of the region's innovation system and its significance for the formation of the development pole of the subject of the federation allows us to propose the following definition of the mechanism of its communication support.

\subsection{The mechanism of communication support of the regional innovation system}

The mechanism of communication support of the regional innovation system is a set of equipment that allows for the exchange of information between participants in the processes of creation and production application of scientific and technical innovations based on modern technologies, databases consumed and generated during this process and personnel providing information exchange and maintaining databases data.

Of great importance for ensuring the effectiveness of communication within the framework of the innovation system of a subject of the federation is the definition of the managerial essence of the mechanism of its communication support, which should form the 
information basis for solving applied problems of influencing the processes of creation and functioning of the regional pole of innovative development by generating data necessary for decision-making on coordination of interaction its elements.

The formulation of the problem of regulating the processes of formation and development of regional growth poles should be based on the basic position of scientific management, which considers management as an information process, in which data is exchanged between the subject and the object along a trajectory (closed loop) "management decision - report on the implementation of management decisions. " Fundamental management work proves that the low quality of this process is the most common cause of corporate crises [22,23]. In our opinion, the connecting processes in the organization should be considered as intra-organizational communications, which require the creation of a special communication mechanism. Based on the fact that the regional innovation system and the key element of the innovation development of the constituent entity of the federation are mega-organizations, it should be recognized that the integrity of this system and its fulfillment of the functions of preventive crisis management is determined by the quality of technological and organizational decisions and the adequacy of material, technical and personnel communication processes.

An important feature of the mechanism of communication support of the regional innovation system as an element of the process of managing it in general and the formation and functioning of the development pole in particular is the combination of elements of state regulation and corporate management in its subjective component. From these positions, we note that the communication support mechanism is becoming an information exchange tool between government bodies and governing bodies of organizations and enterprises in conditions where the possibilities of administering are limited by a rather narrow scope of application of state regulations that cannot affect the vast majority of corporate decisions. This provision determines the content and saturation of information flows, of which the priority is to ensure the movement of data of analytical and analytical nature (information necessary for the preparation of management decisions of various types). At the same time, the flow of regulatory and administrative information (imperative managerial decisions) should be considered in terms of the limited need to coordinate the actions of participants in the implementation of state (federal and regional) innovative development programs. According to the position of the authors, which is consistent with research data on the effectiveness of innovative activities [24, 25], the early stages of the processes of creating new technical and technological solutions (sowing, search and venture research) are most effective when their performers are given maximum freedom of action. At the same time, administrative intervention on the part of the investor (both state and non-state) is minimized and limited by budget decisions with strictly limited control in substance and terms.

Of particular importance is this provision in terms of managing the formation and regular activities of the region's innovative development pole, the core of which should be small organizations performing breakthrough developments, the results of which will form the basis for the production of unique innovative products that provide new sources of economic growth for the federal subject.

A functional feature of the mechanism of communication support of the innovation system of a subject of the federation is its service character, which is expressed in the fact that, not being a direct participant in innovative activity (executor of innovative projects), this control element provides information support for work in this area, providing innovative active organizations and enterprises services for the provision and transfer of data at their request. In the economic aspect, the functions of the communication mechanism should be considered as a tool to reduce the costs of participants in innovative activities by transferring to specialized organizations part of the work as part of the 
innovation process, provided that their quality is higher than when they are carried out independently and lower or in a positive relation to the quality of costs.

\section{Results}

When determining the overall composition of the functions of the regional mechanism of communication support it is necessary to take into account the need for his orientation towards a comprehensive solution to the problem of supporting innovative activities in the region, providing all its aspects. At the same time, an important characteristic of the mechanism being studied is not only the provision of primary data, but also their analytical processing and the development of draft decisions in the field of management for executors of innovative projects. The structural-process diagram of the functions of the regional mechanism of communication support of the regional innovation system is shown in Fig.1.

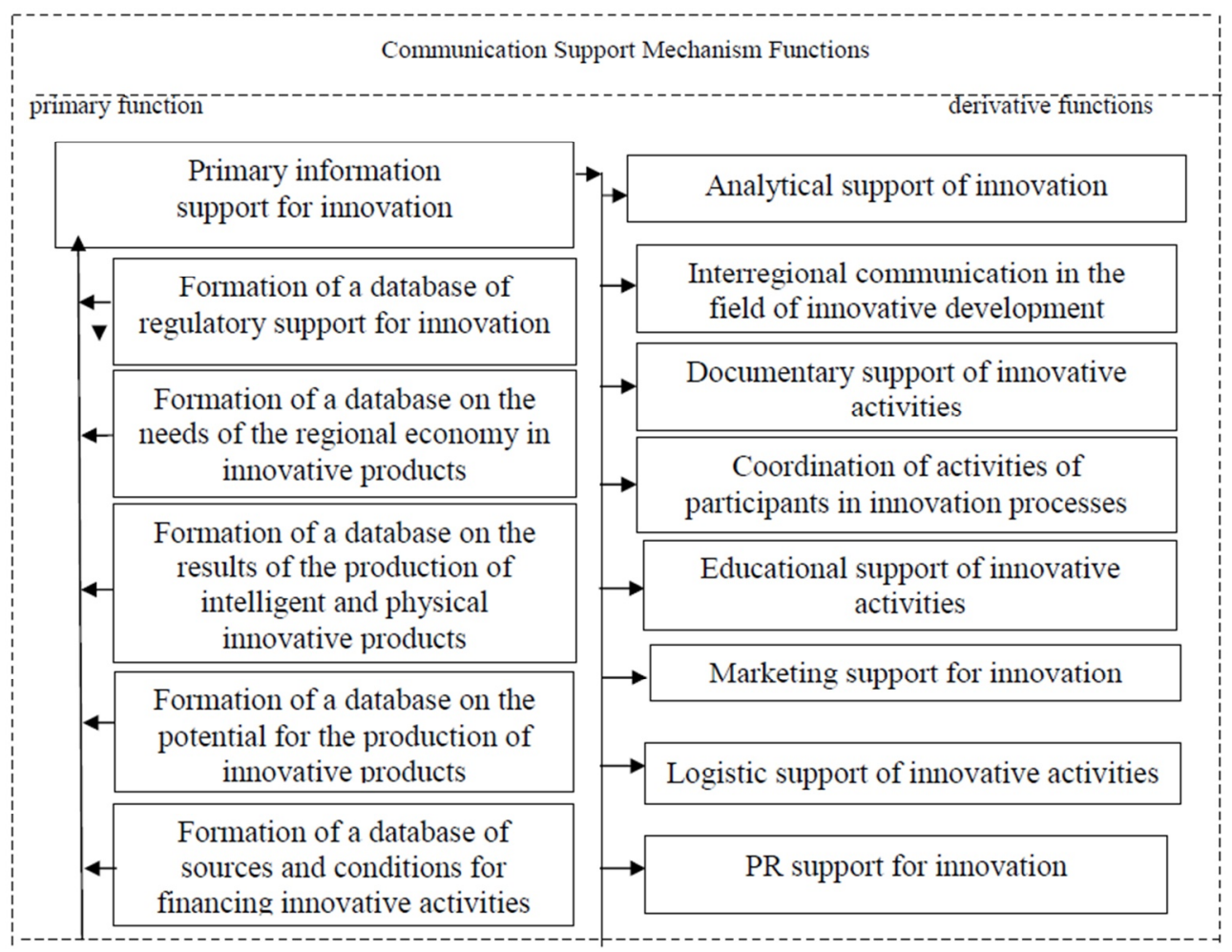

Fig. 1. The structural-process diagram of the functions of the regional mechanism of communication support of the regional innovation system.

The primary information support function of innovation activity, which forms a separate group of subfunctions and is of a complex structural nature, is decisive in relation to the other functions of the communication support mechanism of the regional innovation system, since during its implementation databases are created that can be of independent interest to participants in the processes of creating innovations. However, in a large number of cases, the effectiveness of the mechanism under study is significantly increased if, based on these data, new data are created in the form of analytical and methodological materials that allow their consumers to increase the degree of validity and efficiency of managerial decision-making. The primary information support function should be oriented towards the creation of the following databases: 
- data on federal and regional regulatory support of innovative activities, including state programs of innovative development, in which regional economic entities can take part, as well as a full commented text of laws and government regulations governing the implementation of work on the creation and application of scientific and technical innovations;

- data on the needs of the regional economy for innovative

products reflecting the market demand for innovations, structured by industry, by profile of activity (for example, by the OKVED articles), by type of need (local or common for several consumers), by the method of acquisition (contract for the acquisition or for the implementation of scientific and technical works ), according to the parameters of consumer organizations (for example, by the volume of activity, by organizational and legal status, by type of ownership) and by other signs reflecting the regional specificity of consumption of innovative products comrade;

- data on the results of the production of intellectual and physical innovative products in the region and in the national economy, characterizing the market supply of innovations and presented as an annotated list of scientific and technical products (completed developments) and modern goods and services based on innovative solutions and classified by market segments the highest consumer value for regional economic entities;

- data on the potential of regional and national production of intellectual and physical innovative products, which make it possible to objectively assess the possibilities of carrying out scientific and technical work (production of intellectual products) and the production of goods and services that correspond in their purpose and innovativeness to the needs of the socio-economic system of the subject of the federation able in the future to become the subject of commercialization;

- data on the sources and conditions of financing innovative activities in the region and beyond, presented both by investment companies and banks, and distributed by groups of investment methods and directions, including direct and portfolio investors, venture investors, and industry-specific investors, investors focused on industrial investments, universal investors.

The group of derivative functions of the mechanism of communication support of the innovation system of the region should comprise the following elements.

The function of analytical support of innovative activity in the region is to obtain objective assessments of the state of the sphere of innovative activity in the region on the basis of databases generated during the implementation of the primary function of information support (in the context of the classification criteria used), to identify stable trends in this object and to make verified forecasts of it development. The condition for the implementation of this function is the correct use of the modern apparatus of macro and mesoeconomic analysis and the reflection of statistically parameters formed using methodological tools for monitoring the innovation sphere [26, 27].

The function of inter-regional communication in the field of innovative development involves the formation of horizontal information links between the subjects of innovative activity in different regions, including state authorities of the regions and organizations and enterprises located in their territory. The implementation of this function can be focused on reflecting the activities of the Association of Innovative Regions of Russia (AIRR), created by decision of the XII Innovation Forum Innovus, the purpose of which is to "promote the effective innovative development of the participating regions, based on the recognition of the various different models of scientific and technological growth of the regions "[28].

The function of documentary support of innovation activity, the implementation of which will allow solving many organizational problems in the field of interaction between subjects of innovation activity, consists in preparing draft contracts for the supply of products and services (including scientific and technical nature) that objectively take into 
account the interests and capabilities of the parties and are well positions of formal legal requirements.

The function of coordinating the activities of participants in innovation processes is focused on creating the conditions (from providing recommendations to the direct execution of work) of the development and monitoring of the implementation of innovative projects. The basis for the implementation of this function should be the parameters of contracts (concluded using the resources of the communication support mechanism or independently by the project co-executors) and the application of modern foreign and domestic methods of investment and innovative design.

The labor support function of innovation activity is the execution of a set of works aimed at meeting the current staffing needs of participants in innovation activity, which can be either general (associated with the innovation activity of a given organization as a whole) or specialized (related to the implementation of a specific innovation project). The essence of this function is to study the proposals of the regional and national labor market in the context of professions and the qualification level of workers in the field of innovation and, on behalf of its participants, to analyze such proposals (up to qualified interviews with applicants).

The function of educational support of innovative activities reflects the process of satisfying the prospective staffing needs of innovatively active organizations and enterprises and should include the organization of the educational process, which allows preparing employees of various categories, professions and qualifications due to the participation of these entities in innovative processes. From these positions, the leading principle of the implementation of the educational support function should be recognized as comprehensiveness, which will allow harmonizing with the interests of the employer the qualitative, quantitative and time parameters of the training process for workers of specialized professions, mid-level specialists, personnel with higher professional education (including postgraduate).

The marketing support function of innovation activities is aimed at the implementation of a range of activities aimed at market promotion and market positioning of innovations based on the use of individually oriented marketing and network marketing tools through various types and types of presentation events. The objects of marketing in the innovation sphere should be not only the innovative products offered by regional manufacturers (goods, technologies, results of scientific and technical work), but organizations and enterprises located in the territory of this subject of the federation and capable of acting as suppliers of innovation in the regional and national markets.

The function of logistic support of innovative activities should be considered as the formation of effective incoming and outgoing material flows of participants in innovative processes. This function is especially significant for innovative projects at the production stage where the volume of deliveries is high, meeting deadlines is a critical characteristic of efficiency, ensuring the established parameters for acquiring and selling requires high costs, and non-observance leads to higher costs. However, in the pre-production stages (research and development), in a large number of cases, logistical problems arise (for example, the supply of special equipment), the solution of which requires a professional approach.

The function of PR-support of innovative activities should ensure the formation of effective relations of participants in innovative activities with the public, represented by target contact audiences, including regional (or regional branches of national) non-profit organizations with different profiles. Such organizations may include, for example. environmental communities, scientific societies and councils, commissions and committees for monitoring the state of affairs in education and others).

The formation of a holistic and consistent (eliminating duplication) functional composition of the mechanism of communication support of the regional innovation system 
allows providing an effective solution for creating its mega-organizational structure and applying the complex of scientific management functions to the management of this object.

\section{Conclusion}

Thus, information-technological and communication support of the objects of production and social spheres of the regions in the process of their current innovative activity and longterm development, aimed at: meeting the requirements for establishing and observing institutional norms and rules of innovative activity; determining the forms and methods of action of innovative entities organizations, harmonization of their interests; Institutional regulation of the functioning of the regional mechanism of communication support of the innovation system of the region allows: to dampen objectively existing contradictions in the interests of public and private objects of management of innovative processes and to develop agreed norms and rules for the implementation of innovative activities; highlight as part of the regional innovation subsystem

The function of the development pole of organizations; draw up an informational basis for the impact on the processes of creation and functioning of the regional pole of innovative development; use the functions of the communication mechanism as a tool to reduce the costs of regional participants in innovation.

\section{References}

1. The development strategy of the information society in the Russian Federation for 2017 - 2030 (2017)

2. Science. Innovation Information Society 2010 (Higher School of Economics State University, 2014)

3. The state program of the Russian Federation "Information Society" (2014)

4. The concept of regional informatization (Government of the Russian Federation, 2014)

5. D. Cleland, V. King, System analysis and target management (Book, Moscow, 2011)

6. K. Morgan, Regional Studies 31, 491-503 (1997)

7. B. Asheim, M. Gertler, Understanding regional innovation systems. Handbook of Innovation (Oxford University Press, Oxford, 2004)

8. V. Krolivetskaya, E. Krolivetsky, E3S Web Conf. 135, 04032 (2019) doi: 10.1051/e3sconf/201913504032

9. H. Capron, M. Cincera, The Flemish innovation system: an external viewpoint (IWT Observation, Brussels, 1998)

10. E.I. Markovskaya, V.V. Holodkova, D.A. Radushinsky, Journal of Corporate Finance Research 13(2), 104-113 (2019) doi: 10.17323/j.jcfr.2073-0438.13.2.2019.104-113

11. G.B. Kleiner, Institutional economics and modern management: monograph (State University of Management, Moscow, 2016)

12. T. Veblen, Theory of the idle class (Progress, Moscow, 1984)

13. J.R. Commons, Institutional Economics: Its Place in Political Economy (University of Wisconsin Press, Madison, 1934)

14. D. North, Institutions, institutional change and the functioning of the economy (Beginnings, Moscow, 1997)

15. A. Shleifer, E. Glaeser, R. La Porta, F. Lopezde-Silanes, Journal of Economic Growt 9, 271-303 (2004) 
16. E.G. Furubotn, R. Richter, Institutes and economic theory: Achievements of the new institutional economic theory (St. Petersburg. state University, SPb, 2005)

17. S.D. Bodrunov, The Future. New industrial society: reboot (INIR, SPb, 2016)

18. T.A. Sorvina, Journal of Legal and Economic Research 2, 234-237(2019)

19. E.N. Krolivetsky, A.M. Melnichenko, Journal of legal and economic studies 1, 133136 (2018)

20. D.A. Radushinsky, S.V. Zdolnikova, Scientific and Technical Journal of St. Petersburg State Polytechnical University. Economic sciences 5(204), 54-63 (2015) DOI: 10.5862/JE.228.5

21. GOST 27.004-85 Reliability in technology (SSTN), http://docs.cntd.ru/document/1200009412

22. V.G. Rogovoi, N.D. Bagretsova, Crisis management in the economy of new challenges (2014)

23. A.V. Bataev, A.A. Gorovoy, A.B. Mottaeva, Proceedings of the 32nd International Business Information Management Association Conference, IBIMA 2018 - Vision 2020, 102-114 (2018)

24. A.O. Baranov, E.I. Muzyko, V.N. Pavlov Evaluation of the effectiveness of innovative projects using optional and fuzzy-multiple approaches (IEOPP SB RAS, Novosibirsk, 2018)

25. D. Radushinsky, E. Markovskaya, etc., MATEC Web of Conferences (SPbWOSCE2017 Business Technologies for Sustainable Urban Development), 01047 (2018) DOI: $10.1051 /$ matecconf / 201817001047

26. E.A. Baykov, A.D. Evmenov, N.A. Wrinkle, Strategic management: a training manual (SPbGIKiT, SPb, 2015)

27. T.A. Sorvina, Russian Economic Internet Journal 2, 80 (2019)

28. Association of innovative regions of Russia, http://i-regions.org 